\title{
The effects of family physician-contracted service on health-related quality of life and equity in health in China
}

\author{
Sha Lai ${ }^{1}$, Li Lu², Zhongliang Zhou ${ }^{1 *}$, Chi Shen ${ }^{1}$, Xiaowei Yang ${ }^{1 *}$, Yaxin Zhao ${ }^{1}$ and Xiaolong Zhang ${ }^{1}$
}

\begin{abstract}
Background: Family physician-contracted service (FPCS) has been recently implemented in Chinese primary care settings. This study was aimed at measuring the effects of FPCs on residents' health-related quality of life (HRQLL) and equity in health among the Chinese population.

Methods: The study data was drawn from the 2018 household health survey (Shaanxi Province, China) using multistage, stratified cluster random sampling. We measured HRQoL using EQ-5D-3L based on the Chinese-specific time trade-off values set. Coarsened exact matching (CEM) technique was used to control for confounding factors between residents with and without a contracted family physician. The concentration index (C) was calculated to measure equity in health.

Results: Individuals with a contracted family physician had significantly higher HRQOL than those without, after data matching $(0.9355$ vs. 0.8995; $P<0.001)$. Additionally, the inequity in $\mathrm{HRQOL}$ among respondents with a contracted family physician was significantly lower than those without a contracted family physician (Cs of EQ-5D utility score: 0.0084 vs. $0.0263 ; p<0.001$ ).

Conclusions: This study highlights the positive effects of FPCs on HRQOL and socioeconomic-related equity in HRQoL. Future efforts should prioritize the economically and educationally disadvantaged groups, the expansion of service coverage, and the competency of family physician teams to further enhance health outcome and equity in health.
\end{abstract}

Keywords: Family physician, Health-related quality of life, Equity in health, China

\section{Background}

Family physician (also known as the general practitioner) system is considered as the core of primary care and has gained rapid ground worldwide [1-3]. Primary care services provided by family physician enhance the continuity and coordination of care, reduce the inappropriate use of specialty services, and improve a population's health [4-6]. The Chinese government has explored and

\footnotetext{
*Correspondence: zzliang1981@163.com; yangxwde@mail.xjtu.edu.cn 'School of Public Policy and Administration, Xi'an Jiaotong University, No. 28 West Xianning Road, Xi'an 710048, Shaanxi, China

Full list of author information is available at the end of the article
}

established a hierarchical medical system to suit the national conditions in recent years [7]. The hierarchical medical system emphasizes the importance of a clear division of health care roles and responsibilities for different levels of hospitals, and highlights the significance of taking strategies to encourage the utilization of primary care [8]. The implementation of the family physician-contracted service (FPCs) is one of the key actions, which improve people's access to primary health care, minimize the unfair distribution of medical resources and improve the health of community residents [9-11].

(c) The Author(s). 2021 Open Access This article is licensed under a Creative Commons Attribution 4.0 International License, which permits use, sharing, adaptation, distribution and reproduction in any medium or format, as long as you give appropriate credit to the original author(s) and the source, provide a link to the Creative Commons licence, and indicate if changes were made. The images or other third party material in this article are included in the article's Creative Commons licence, unless indicated otherwise in a credit line to the material. If material is not included in the article's Creative Commons licence and your intended use is not permitted by statutory regulation or exceeds the permitted use, you will need to obtain permission directly from the copyright holder. To view a copy of this licence, visit http://creativecommons.org/licenses/by/4.0/ The Creative Commons Public Domain Dedication waiver (http://creativecommons.org/publicdomain/zero/1.0/) applies to the data made available in this article, unless otherwise stated in a credit line to the data. 
Family physician-contracted services were officially launched throughout China in June 2016 after pilot projects in 200 selected areas [12]. Family physiciancontracted services target the entire population, focusing on the elderly, pregnant women, children, people with disabilities, and patients with hypertension, diabetes, tuberculosis and other chronic diseases. The public is being encouraged and guided to contract with nearby family physician teams who are responsible for the provision of proactive, continuous, and comprehensive health care [12]. Family physician-contracted services are being explored and implemented in various regions of China. For example, in Shaanxi province (part of Northwest China), the FPCs - fully launched in 2016-provides 'free service package + paid service package' and its operational cost is partly subsidized from the regional funds of medical insurance and basic public health program [13]. The free service package was designed to provide basic public health services: such as establishing and managing personal health records, health education, health literacy promotion, and primary care management of chronic diseases. The paid service package includes basic medical services and personalized health management services. The residents who are contracted with a family physician can enjoy free or low-cost healthcare services from the family physician team, which include family physicians, nurses, public health practitioners.

The effects of FPCs have been widely reported in previous studies. Family physician-contracted services can improve the continuity, comprehensiveness, and coordination of primary care services [14-16]. This service also helps individuals with chronic diseases to improve their health-related awareness, self-management behaviors, and treatment compliance $[17,18]$. For example, a population-based retrospective cohort study in Canada suggested that family physician care can reduce hospitalizations in elderly people with diabetes [19]. Another randomized controlled trial study in Norway identified that in addition to geriatrician, clinical assessments and medication reviews from collaborative team including family physicians can improve health-related quality of life (HRQoL) in older patients exposed to polypharmacy [20]. However, one Iranian study indicated that family physician program had a positive effect on the proximal health indicators in maternal and child health (e.g., birth weight), but no substantial effect on mortality [21]. One study from South Africa did not find a positive association between the supply of family physician and health indicators (i.e., maternal mortality, perinatal mortality and under-five mortality) [22]. The inconsistencies among existing studies could be partly attributed to different health indicators that were used.

Existing studies concerning the effects of FPCs on health in China are mainly limited on improving health outcomes in patients with chronic diseases. For example, previous studies have shown that FPCs have positive effects on hypertension control rates among patients with hypertension [18, 23]. Unfortunately, in China, whether family physician-contracting services could improve HRQoL and health equity in the general population has not been extensively studied.

Therefore, we conducted this study using the data from a household health survey in Shaanxi Province, China, with the aim to (1) explore whether being contracted with family physician services can improve HRQoL, (2) investigate whether the inequity in HRQoL would be lessened under the implementation of FPCs, which might provide implications for policymakers in terms of advancing family practice contract services in China. Based on previous research $[15,24-26]$, we hypothesize that FPCs would help improve community residents' HRQoL and lessen the inequity in HRQoL.

\section{Methods \\ Data sources}

Data were derived from the 2018 cross-sectional household health survey that was conducted in three districts and two counties in Shaanxi Province, an area about $205,800 \mathrm{~km}^{2}$ in northwest China with a population of 37.9 million.

Participants were recruited by multistage, stratified cluster random sampling. In short, out of 5 districts or counties, 25 sub-districts or townships were randomly selected. Out of those sub-districts, we randomly selected 50 communities or villages (two for each subdistrict or township). All members from 3000 households including 7819 individuals were collected. Only participants aged 15 years and above were included in this study, since children who were below 15 years could not answer several questions regarding socioeconomic characteristics and health status. Finally, 6503 individuals were included in the analyses.

\section{Measures}

Pre-trained interviewers conducted face-to-face interviews by structured questionnaire, and collected the following information: sociodemographic characteristics, economic characteristics, health status, health services coverage, and health services utilization.

Sociodemographic and economic characteristics include the following information: sex, age group (15-44 years/4559 years/60 years and above), educational level (primary and below/junior middle school/senior middle school/ college and above), marital status (unmarried/married/others), employment status (unemployed/employed), commercial medical insurance (with/without), minimum travel time to the nearest health-care facility (within $15 \mathrm{~min} /$ more than $15 \mathrm{~min}$ ), basic medical insurance (Urban Employee Basic 
Medical Insurance [UEBMI]/Urban-Rural Resident Basic Medical Insurance [URRBMI]), chronic conditions (yes/ no), and residential areas (urban or rural areas). The household consumption expenditure per equivalent adult was used as a proxy measure of economic status. We divided the household consumption expenditure per equivalent adult into five groups, the first quintile represents the poorest economic group (i.e., the lowest $20 \%$ ) while the fifth quintile represents the wealthiest economic group (i.e., the highest 20\%).

We inquired whether responders had contracted with a family physician by asking "Are you contracted with a family physician?", which they could respond with "yes" (scored as 1) and "no" or "I've heard nothing of this services" (scored as 0 ).

Health-related quality of life (HRQoL) combines physical and mental health into a summary score, which ranges from 0 (death) to 1 (perfect health). Notably, certain scores can also measure states worse than death [27], such as an index score of EQ-5D ranges - 0.59 (worst possible health state) to 1 (best possible health states) according UK tariffs, and by construction, the value of 0 is equal to death and negative values represent HRQoL worse than being dead [28]. In our study, HRQoL was measured by the health utility values for the validated Chinese version of the EuroQol fivedimensional questionnaire-three-level version (EQ-5D$3 \mathrm{~L})[29,30]$. The questionnaire includes five questions and consists of five dimensions, i.e., responder's mobility, self-care, usual activities, pain or discomfort, and anxiety or depression; each dimension has three response levels $(1=$ no problems, $2=$ moderate problems and $3=$ extreme problems). We employed the Chinese time tradeoff values for EQ-5D-3L to measure the utility values of the EQ-5D-3L [31], which has also been widely used in other studies [32,33]. The overall utility values of EQ5D-3L ranges from -0.149 (having extreme problems) to 1 (no problems).

\section{Statistical analyses \\ Matching method}

Coarsened exact matching (CEM) The pretreatment covariates differ between the groups with and without FPCs for the observational data, the Coarsened Exact Matching (CEM) technique is designed to improve the estimation of causal effects via a powerfully matching method to keep a better balance of distributions of the covariates between groups, and thereby reducing the bias [34]. The idea of CEM is to temporarily coarsen each variable into substantively meaningful groups, match on these coarsened data exactly, and then only retain the original (uncoarsened) values of the matched data [35]. We applied the CEM method to control confounding variables between the two groups to investigate whether a contracted family physician could improve HRQoL and promote health equity. The detail of technique is well described in detail in previous literatures $[34,35]$. The STATA cem command was used to perform the CEM algorithm [35].

There is a comprehensive imbalance measure $L_{1}$ statistic, which was used to check the overall imbalance. The calculation for $L_{1}$ is as follows: first, we coarsened the covariates into bins, then cross-tabulated the discretized variables as $X_{1} \times \ldots \times X_{k}$ for the groups with and without FPCs separately, and recorded the $\mathrm{k}$-dimensional relative frequencies for the group with FPCs $f_{e_{1} \ldots e_{k}}$ and for the control $g_{e_{1} \ldots e_{k}}$ units. Finally, the absolute difference over all the cell values is defined as the measure of imbalance $L_{1}:[35]$.

$$
L_{1}(f, g)=\frac{1}{2} \sum_{e_{1} \ldots e_{k}}\left|f_{e_{1} \ldots e_{k}}-g_{e_{1} \ldots e_{k}}\right|
$$

$L_{1}$ ranges from 0 (perfect global balance) to 1 (maximal imbalance). A substantial reduction in $L_{1}$ means a good matching performance. In this study, we focused on matching the following covariates: sex, age, chronic conditions, economic status, educational level, employment status, marital status, medical insurance, spatial accessibility of health-care facility, and residential areas.

\section{Tobit regression models}

(a) Concentration index (C) We measured the degree of socioeconomic-related inequality in HRQoL between the two groups in our study using the concentration index $(\mathrm{C})$, which is a widely used parameter [36, 37]. The $C$ takes values in the range $[-1,1]$; a value of 0 means perfect equality, a positive value signifies pro-rich bias while a negative value signifies pro-poor bias. The $\mathrm{C}$ formula is

$$
\mathrm{C}=\frac{2}{\mu} \operatorname{cov}\left(y_{i}, r_{i}\right)
$$

where $y$ is the health variable (i.e., the utility values of the EQ-5D in this study), $\mu$ is mean of the EQ-5D utility value, $r_{i}$ (rang $\left.[0,1]\right)$ is the fractional rank of the $i$ th individual in the economic distribution.

(b) Decomposition analysis for $\mathbf{C}$. The decomposition analysis was based on a regression model that decomposes $\mathrm{C}$ into its contributing factors. Tobit regression was applied to calculate the partial effects of regressors, owing to the outcome variables (i.e., the utility values of EQ-5D) which were limited variables [38]. Health $(y)$ is modelled as follows: [36]. 


$$
y_{i}=\sum_{k} \beta_{k} x_{k i}+\varepsilon_{i}
$$

$\beta_{k}$ are the partial effects, $\varepsilon$ is the error term, while $x_{k}$ are the means of explanatory variables. $\mathrm{C}(y)$ can be decomposed as: [36].

$$
\mathrm{C}=\sum_{k}\left(\frac{\beta_{k} \bar{x}_{k}}{\mu}\right) C_{k}+\frac{G C_{\varepsilon}}{\mu}
$$

$C_{k}$ is the concentration index of explanatory variables and $G C_{\varepsilon}$ is the generalized concentration index of $\varepsilon$. The deterministic component is $\sum_{k}\left(\frac{\beta_{k} \bar{x}_{k}}{\mu}\right) C_{k}$, while the residual component is $\frac{G C_{\varepsilon}}{\mu}$. The contribution of each factor depends on its impact on health and the degree of unequal distribution across the economic gradient. The percentage contribution of each regressor $\left(100 Q_{k} / C\right)$ was also calculated, and it can take both positive and negative values. We further calculated the age-sex adjusted $\mathrm{C}$ (also known as the horizontal inequity index)-which represents the potentially avoidable inequality-by subtracting the contributions of age and gender from the total C [39].

Standard errors were adjusted for clustering at the family level for all models. Statistical analyses were conducted using the STATA version 14.0 (Stata Corporation, College Station, Texas, USA) with the significance level as a $P<0.05$ (two-tailed).

\section{Results}

Demographic characteristics of responders and matching performances

Table 1 represents basic sociodemographic and economic characteristics of the respondents before and after data matching. A total of 6503 respondents were included, and data from 4612 individuals were further analyzed after data matching. Prior to data matching, the proportion of respondents aged 60 and above, having chronic conditions, with middle and below economic status, with junior middle school and below education, having Urban-Rural Resident Basic Medical Insurance, and living in rural region in group with FPCs was greater than group without FPCs. After matching using CEM method, covariates imbalances were eliminated between the two groups. Table 2 shows $L_{1}$ statistics of each variable, and multivariate $L_{1}$ statistics before and after data matching. Consistently, in the two groups, $L_{1}$ values of each variable decreased and were close to zero after data matching.

\section{Description of EQ-5D and its concentration index}

The utility values of EQ-5D and its each dimension are presented in Table 3. After data matching, the mean EQ-5D utility values between respondents with FPCs were 0.9355 (95\% CI: 0.9302-0.9409), and without FPCs were 0.8995 (95\% CI: 0.8926-0.9063). The Cs of EQ-5D score for the respondents with a contracted family physician was significantly lower than those without a contracted family physician $(0.0084,95 \%$ CI: $0.0047-$ 0.0122 vs. $0.0263,95 \%$ CI: $0.0187-0.0340 ; P<0.001$ ), suggesting that the pro-rich bias was slightly reduced by contracting family physician services.

\section{Decomposition of inequality of HRQoL}

Table 4 presents the decomposition results of $\mathrm{Cs}$ of the overall EQ-5D scores. The partial effects, absolute contribution and percentage contribution of each determinant to the inequality of the overall EQ-5D score are presented.

Partial effect estimates indicated that among respondents with a contracted family physician, those aged 45 years and above, having chronic conditions, and married, divorced and widowed status were more likely to have lower overall HRQoL. Among those who did not contract with a family physician, the following factors were negatively associated with the overall HRQoL: aged 60 years and above, presence of chronic conditions, low economic status and educational level, divorced and widowed status, living in rural areas and far from healthcare facilities.

A positive contribution to inequality means that the relevant determinant increases pro-rich inequality and vice versa. For those with a contracted family physician, the top three categories of residents with the greatest inequality in HRQoL were: aged 60 years and above (90.49\%), having at least college-level education (79.44\%) and richest economic status (68.10\%). For those without a contracted family physician, the following factors had the largest positive contributions in explaining the inequality of HRQoL: richest economic status (58.62\%), richer economic status (40.61\%), and having at least college-level education (27.01\%). The age-sex adjusted Cs in HRQoL among those with a contracted family physician was lower (0.003) than those without (0.022).

\section{Discussion}

Benefiting from the CEM technique and a representative dataset (the 2018 household health survey in Shaanxi Province, northwest China), our study found that individuals with a contracted family physician had significantly better HRQoL that was measured with EQ-5D-3L than those without. Moreover, it also suggested that the inequities in HRQoL were lower among those who contracted with a family physician than those who did not.

Family physician services are favorably helpful in promoting HRQoL $[20,40]$ - which was reconfirmed in this study showing that the EQ-5D-3L utility value among 


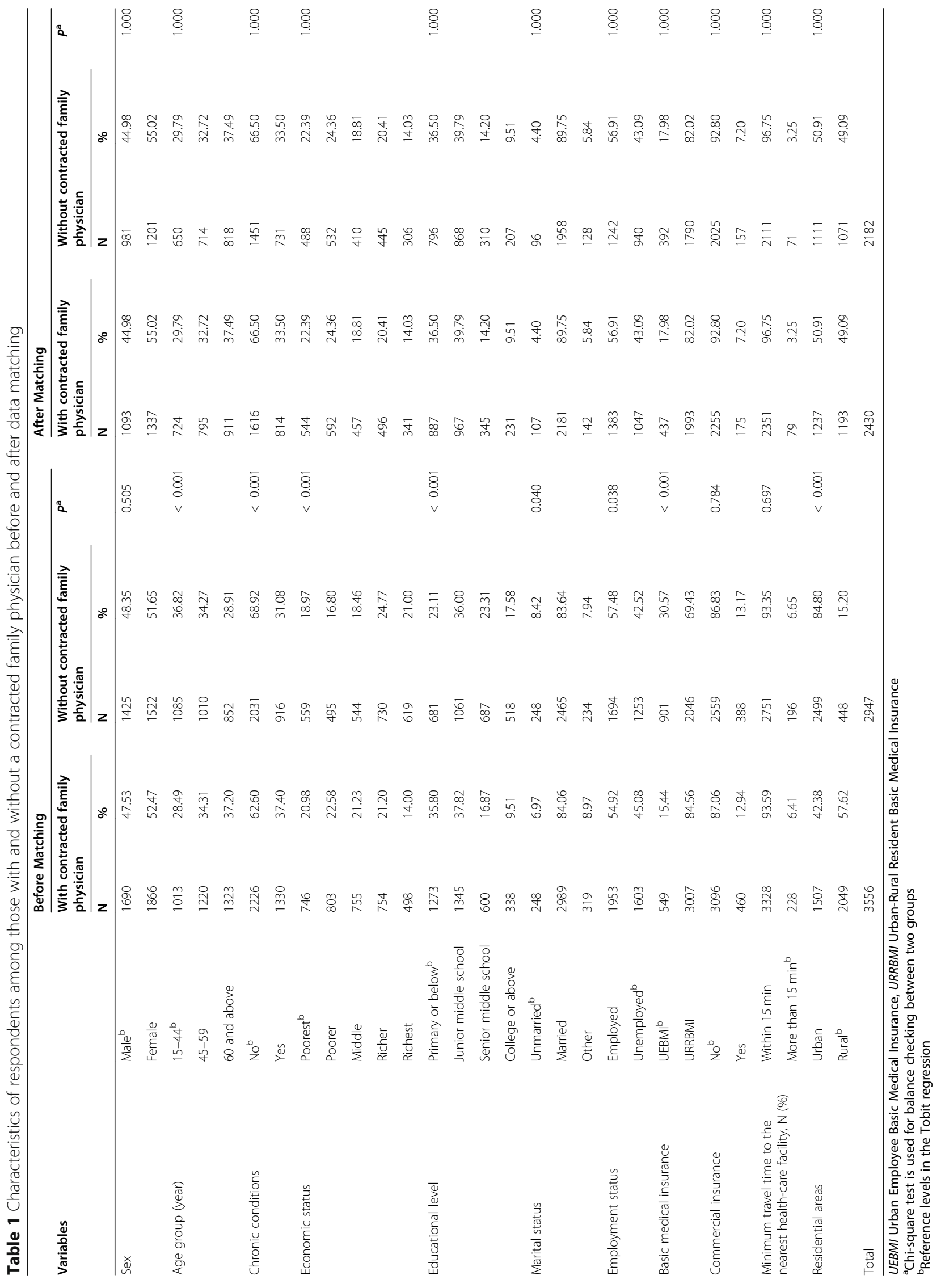


Table 2 The $L_{1}$ measure of imbalance between two groups before and after Coarsened Exact Matching

\begin{tabular}{|c|c|c|c|c|}
\hline \multirow[t]{2}{*}{ Variables } & \multicolumn{2}{|c|}{ Before Matching } & \multicolumn{2}{|c|}{ After Matching } \\
\hline & $L_{1}$ (Mean) & $L_{1}$ (SE) & $L_{1}$ (Mean) & $L_{1}$ (SE) \\
\hline Sex & 0.0083 & 0.0083 & $2.6 \times 10^{-15}$ & $2.9 \times 10^{-15}$ \\
\hline Age group & 0.0833 & 0.1662 & $3.8 \times 10^{-15}$ & $-7.1 \times 10^{-15}$ \\
\hline Chronic conditions & 0.0632 & 0.0632 & $2.2 \times 10^{-15}$ & $2.8 \times 10^{-15}$ \\
\hline Economic status & 0.1057 & -0.2737 & $2.7 \times 10^{-15}$ & $-3.1 \times 10^{-15}$ \\
\hline Educational level & 0.1451 & -0.3527 & $3.2 \times 10^{-15}$ & $-5.3 \times 10^{-15}$ \\
\hline Marital status & 0.0144 & 0.0247 & $3.7 \times 10^{-16}$ & $-4.4 \times 10^{-15}$ \\
\hline Employment status & 0.0256 & 0.0256 & $2.8 \times 10^{-15}$ & $1.3 \times 10^{-15}$ \\
\hline Basic medical insurance & 0.1514 & 0.1514 & $7.9 \times 10^{-16}$ & $-2.4 \times 10^{-15}$ \\
\hline Commercial insurance & 0.0023 & -0.0023 & $6.2 \times 10^{-16}$ & $4.7 \times 10^{-16}$ \\
\hline $\begin{array}{l}\text { Minimum travel time to the nearest } \\
\text { health-care facility }\end{array}$ & 0.0024 & -0.0024 & $1.2 \times 10^{-16}$ & $1.1 \times 10^{-15}$ \\
\hline Residential areas & 0.4242 & 3.3935 & $3.1 \times 10^{-15}$ & $5.5 \times 10^{-14}$ \\
\hline Multivariate $L_{1}$ & 0.5648 & & $3.6 \times 10^{-15}$ & \\
\hline Total, N & 6503 & & 4566 & \\
\hline
\end{tabular}

Note: The overall imbalance is given by $L_{1}$ statistic, introduced in lacus, King, and Porro (2008) as a comprehensive measure of global imbalance. $L_{1}$ reported the $L_{1 j}$ measure, which is $L_{1}$ computed for the $j_{t h}$ variable separated. The mean was labeled in parentheses reported the difference in means

individuals who contracted with family physician services was greater than those who did not $(P<0.001)$. HRQoL is a generic outcome measure to assess the effectiveness of interventions and a way of reflecting one's subjective perceptions and experiences [41]. Impaired HRQoL denotes perceived difficulties and functional limitations in daily life caused by illness [27]. The results also suggested that individuals contracted with a family physician were less likely to have functional limitations in moderate mobility, activity, pain and moderate anxiety. On the one hand, the health care services delivered by the family physicians include medicine and physical therapies, rehabilitation services, health counseling and the referral services. These proactive, continuous and comprehensive health care services could help enhancing the physical ability and mental health of contracted patients, such as relieving pain, improving mobility and activity, relieving depression and anxiety. On the other hand, the long-term cooperative relationships between contracted family physicians and residents promotes trust in primary care physicians among residents, which were identified to be associated with lower depression and anxiety in patients [42]. FPCs is a comprehensive strategy that strives to ensure equitable access, continuity of care, coordination and comprehensiveness of care in primary healthcare. Previous literature has identified the remarkable effects of FPCs in improving the quality and utilization of primary healthcare services [16, 43], which are highly correlated with better health outcomes, including total and specific mortality, life expectancy, and other health outcome indices, e.g., self-rated health, HRQoL [24].
Our study found that the pro-rich bias was slightly reduced by family physician-contracted services; age-sex adjusted Cs in HRQoL were 0.003 among the group with FPCs, and 0.022 among the group without FPCs-indicating the role of FPCs in reducing health disparities. Striking differences in health outcome still exist within and between populations, so equity is an important goal in health sectors. The primary healthcare system is important to promote equity in access and health outcome of a population, yet primary healthcare services are not always readily accessible for some populations in China [44]. The FPCs in China established a long-term contracted relationship between residents and family physicians. They provide comprehensive clinical care and health management services to the contracted populations, and promote information exchange; thus helping to improve the accessibility of primary health services [45]. The cost of FPCs is partially subsidized by public finances, which may reduce barriers to healthcare utilization for disadvantaged groups and thereby improving their health status [46].

From a policy perspective, improvement in health equity needs a broader focus that addresses socioeconomic determinants of health and health equity. The current FPCs gives the high-need populations, such as the elderly, pregnant women, children, people with disability, and people with chronic diseases, the top priority to primary healthcare services in our sample areas. Our findings suggested that lower socioeconomic status, i.e., lower educational level, unemployment, poor spatial accessibility, and living in rural areas were associated with lower HRQoL. In addition, economic status and 
Table 3 Description of EQ-5D health state and economic-related inequality in EQ-5D scores between respondents with and without contracted family physician

\begin{tabular}{|c|c|c|c|c|c|c|c|c|c|c|c|}
\hline & \multicolumn{5}{|c|}{ Before matching } & \multicolumn{5}{|c|}{ After matching } \\
\hline & & \multicolumn{2}{|c|}{$\begin{array}{l}\text { With contracted } \\
\text { family physician }\end{array}$} & \multicolumn{2}{|c|}{$\begin{array}{l}\text { Without contracted } \\
\text { family physician }\end{array}$} & \multirow[t]{2}{*}{$p$} & \multicolumn{2}{|c|}{$\begin{array}{l}\text { With contracted } \\
\text { family physician }\end{array}$} & \multicolumn{2}{|c|}{$\begin{array}{l}\text { Without contracted } \\
\text { family physician }\end{array}$} & \multirow[t]{2}{*}{$p$} \\
\hline & & Mean & $95 \% \mathrm{Cl}$ & Mean & $95 \% \mathrm{Cl}$ & & Mean & $95 \% \mathrm{Cl}$ & Mean & $95 \% \mathrm{Cl}$ & \\
\hline \multirow[t]{2}{*}{ Mobility } & Moderate problem & 0.0928 & $(0.0837,0.1028)$ & 0.0926 & $(0.0827,0.1037)$ & $<0.001$ & 0.0947 & $(0.0836,0.1070)$ & 0.1498 & $(0.1354,0.1654)$ & $<0.001$ \\
\hline & Extreme problem & 0.0076 & $(0.0052,0.0111)$ & 0.0078 & $(0.0052,0.0117)$ & 0.249 & 0.0058 & $(0.0034,0.0097)$ & 0.0102 & $(0.0067,0.0154)$ & 0.150 \\
\hline \multirow[t]{2}{*}{ Selfcare } & Moderate problem & 0.0397 & $(0.0337,0.0466)$ & 0.0336 & $(0.0277,0.0407)$ & 0.434 & 0.0383 & $(0.0313,0.0467)$ & 0.0549 & $(0.0461,0.0653)$ & 0.065 \\
\hline & Extreme problem & 0.0096 & $(0.0068,0.0134)$ & 0.0088 & $(0.0060,0.0129)$ & 0.422 & 0.0082 & $(0.0053,0.0127)$ & 0.0141 & $(0.0099,0.0200)$ & 0.165 \\
\hline \multirow[t]{2}{*}{ Activity } & Moderate problem & 0.0560 & $(0.0489,0.0640)$ & 0.0506 & $(0.0432,0.0591)$ & 0.117 & 0.0556 & $(0.0471,0.0654)$ & 0.0755 & $(0.0651,0.0874)$ & 0.045 \\
\hline & Extreme problem & 0.0200 & $(0.0159,0.0251)$ & 0.0227 & $(0.0179,0.0288)$ & 0.002 & 0.0181 & $(0.0135,0.0242)$ & 0.0431 & $(0.0353,0.0525)$ & $<0.00$ \\
\hline \multirow[t]{2}{*}{ Pain } & Moderate problem & 0.1997 & $(0.1868,0.2131)$ & 0.2029 & $(0.1888,0.2178)$ & $<0.001$ & 0.2008 & $(0.1854,0.2172)$ & 0.2707 & $(0.2525,0.2898)$ & $<0.00$ \\
\hline & Extreme problem & 0.0087 & $(0.0061,0.0124)$ & 0.0143 & $(0.0105,0.0192)$ & 0.001 & 0.0082 & $(0.0053,0.0127)$ & 0.0318 & $(0.0252,0.0400)$ & $<0.001$ \\
\hline \multirow[t]{2}{*}{ Anxiety } & Moderate problem & 0.0906 & $(0.0815,0.1004)$ & 0.0882 & $(0.0785,0.0990)$ & 0.102 & 0.0897 & $(0.0790,0.1017)$ & 0.1196 & $(0.1067,0.1340)$ & 0.016 \\
\hline & Extreme problem & 0.0051 & $(0.0032,0.0080)$ & 0.0071 & $(0.0046,0.0109)$ & 0.178 & 0.0041 & $(0.0022,0.0076)$ & 0.0059 & $(0.0034,0.0101)$ & 0.555 \\
\hline \multicolumn{2}{|c|}{ EQ-5D scores } & 0.9341 & $(0.9295,0.9386)$ & 0.9322 & $(0.9272,0.9372)$ & $<0.001$ & 0.9355 & $(0.9302,0.9409)$ & 0.8995 & $(0.8926,0.9063)$ & $<0.00$ \\
\hline \multicolumn{2}{|l|}{$C_{E Q-5 D}$} & 0.0084 & $(0.0052,0.0116)$ & 0.0137 & $(0.0114,0.0161)$ & 0.029 & 0.0084 & $(0.0047,0.0122)$ & 0.0263 & $(0.0187,0.0340)$ & $<0.00$ \\
\hline
\end{tabular}

Note: 95\% Cl: 95\% Confidence Interval, C: Concentration Index

Statistically differences $(P<0.05)$ in each dimension of EQ-5D between two groups based on Multinomial logistic regression ("No problem" was set as the base outcome); statistically differences $(P<0.05)$ in utility values of EQ-5D between two groups based on Tobit regressions; all regression adjusted for sex, age group, chronic conditions, economic status, education level, marital status, working status, basic medical insurance, commercial medical insurance, minimum travel time to the nearest health-care facility and residential areas

educational level were the main sources of inequities in HRQoL among both individuals with and without FPCs. Therefore, authorities need to pay more attention to the economically and educationally disadvantaged groups to further enhance health equity.

Improving health status and the longstanding inequity of health and healthcare still remain as challenges nevertheless there was progress in implementing FPCs and primary healthcare services [10]. Firstly, further efforts to improve people's awareness and willingness to contract with a family physician are required. In Shaanxi province, the signing contract rate among general residents was $54.2 \%$ (according to our full sample data) in 2018. Previous studies showed that the signing contract rates varied greatly in different Chinese regions (30$60 \%$ ) [47-49]. Secondly, the family physician service team should be expanded further to include other allied health professionals such as counselling psychologists, health managers, pharmacists and social workers; this would enhance the capability of the FPCs team to provide better health services [50]. General practitioners, community nurses and public health practitioners are the main components of the current FPCs team, which may not be capable of meeting residents' multifaceted healthcare needs, such as psychological counseling and care services which as we found no significant effects in HRQoL in the dimension of self-care and extreme anxiety. Well-implemented primary healthcare services tend to bring benefits to the most vulnerable in the communities as well as to those with complex healthcare needs [44].

One of our study merits is that we examined the effects of FPCs on health and performed the CEM technique to guarantee better balance of covariate distribution between individuals with and without FPCs. The second is that we used the EQ-5D-3L instrument that was validated among the Chinese general population [30] as a health outcome measure to assess the effect of FPCs on our sample. Some limitations should be noted. Firstly, some unobservable or unmatched factors, such as health literacy and beliefs, may have potential effects on the results. Secondly, the results should be explained as associations rather than causal effects as we used cross-sectional data, thus further longitudinal studies should be conducted. In addition, the severe ceiling effect of EQ-5D-3L cannot be fully eliminated when measuring HRQoL among the general population. Specifically, although $71.7 \%$ of the residents in our study rated themselves as in full health, it was slightly smaller than results in another Chinese study [51]. Lastly, the samples were obtained from one province, and there were heterogeneities regarding FPCs policies and socioeconomic environments between regions, which might limit the study generalizability.

\section{Conclusion}

This study sheds light on the positive effects of FPCs on the HRQoL and socioeconomic-related equity by 


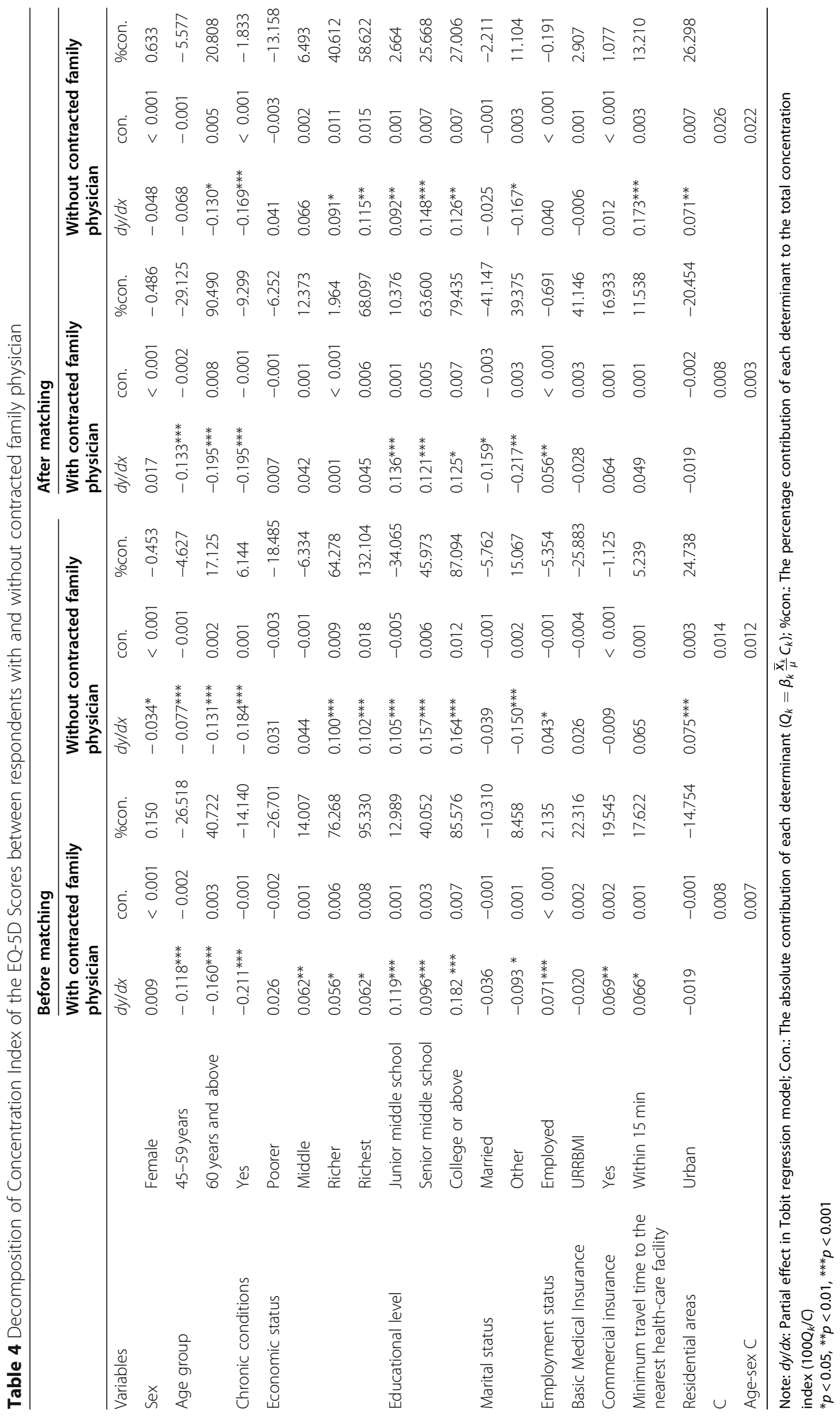


comparing the magnitude of inequalities in HRQoL between the individuals with and without FPCs. To further enhance health equity, authorities should pay more attention to the economically and educationally disadvantaged individuals. Our study provided evidence for policymakers and healthcare institutions to promote and implement FPCs, extend the service coverage of family physicians and enhance the professional competency of family physicians service team.

\section{Abbreviations \\ FPCs: Family physician-contracted service; HRQoL: Health-related quality of life; EQ-5D-3L: EuroOol five-dimensional questionnaire-three-level version; UEBMI: Urban Employee Basic Medical Insurance; URRBMI: Urban-Rural Resident Basic Medical Insurance; CEM: Coarsened Exact Matching; C: Concentration index}

\section{Acknowledgements}

The authors would like to thank all the respondents for their cooperation.

\section{Authors' contributions}

SL conceived of the study, and participated in its design, data analysis and interpretation, and was the primary person responsible for drafting the manuscript. LL participated in writing and revision. ZZ contributed to study design and reviews. CS, YX, ZY and ZX participated in data analysis, reading the draft and provided comments. All authors read and approved the final manuscript.

\section{Funding}

This research was funded by the National Natural Science foundation of China (72004180 \& 71874137), the China Postdoctoral Science Foundation (2019 M653685), and Project of Shaanxi Social Science Foundation (20195038). The Foundations had no role in the study design, data collection, data analysis and interpretation, in the writing of the report, or the decision to submit it for publication.

\section{Availability of data and materials}

The data used in this study belong to the Health Commission of Shaanxi Province and contain the personal information (e.g., name, personal communication information, property status, health condition, physical defect etc.) of participants. The authors were involved in data collection. Due to the sensitive nature of these data and restrictions imposed by the Health Commission of Shaanxi Province, the authors cannot make these data publicly available. Other researchers who want to use the data may submit requests for data access to the Health Commission of Shaanxi Province at sxwjwwz@126.com.

\section{Ethics approval and consent to participate}

Informed consent was obtained from household members before the interview. Approval for this study was obtained by the Ethics Committee of Health Science Center, Xi'an Jiaotong University (approval number 20201256).

\section{Consent for publication}

Not applicable

\section{Competing interests}

The authors declare that they have no competing interests.

\section{Author details}

'School of Public Policy and Administration, Xi'an Jiaotong University, No. 28 West Xianning Road, Xi'an 710048, Shaanxi, China. ${ }^{2}$ Team IETO, Bordeaux Population Health Research Center, UMR U1219, INSERM, Université de Bordeaux, Bordeaux, France.
Received: 12 July 2020 Accepted: 9 December 2020

Published online: 06 January 2021

\section{References}

1. Velasco Garrido M, Zentner A, Busse R. The effects of gatekeeping: a systematic review of the literature. Scand J Prim Health Care. 2011;29:28-38.

2. Racic M, Pekez-Pavlisko T, Jokovic S. Barriers and facilitators for implementation of family medicine-oriented model of primary care in Bosnia and Herzegovina: a qualitative study. Int J Health Plann Manag. 2018; 33:e378-90

3. Kashfi SM, Yazdankhah M, Kashfi SH, Jeihooni AK. The performance of rural family physicians in Fars province, Iran. J Family Med Prim Care. 2019;8:26973.

4. Comino EJ, Davies GP, Krastev Y, Haas M, Christl B, Furler J, Raymont A, Harris MF. A systematic review of interventions to enhance access to best practice primary health care for chronic disease management, prevention and episodic care. BMC Health Serv Res. 2012;12:415.

5. Hespe C, Rychetnik L, Peiris D, Harris M. Informing implementation of quality improvement in Australian primary care. BMC Health Serv Res. 2018; 18:287.

6. Shi L. The impact of primary care: a focused review. Scientifica (Cairo). 2012; 2012:432892.

7. Li X, Lu J, Hu S, Cheng KK, De Maeseneer J, Meng Q, Mossialos E, Xu DR, Yip W, Zhang H, et al. The primary health-care system in China. Lancet. 2017; 390:2584-94.

8. Zhou Z, Zhao Y, Shen C, Lai S, Nawaz R, Gao J. Evaluating the effect of hierarchical medical system on health seeking behavior: a difference-indifferences analysis in China. Soc Sci Med. 2020;268:113372.

9. Yuan S, Wang F, Li X, Jia M, Tian M. Facilitators and barriers to implement the family doctor contracting services in China: findings from a qualitative study. BMJ Open. 2019;9:e032444.

10. Tang $\mathrm{Q}$, Song $\mathrm{P}, \mathrm{Xu} \mathrm{L}$. The role of family physicians contracted healthcare in China: a "Cardiotonic" or a "band-aid" for healthcare reform? Biosci Trends. 2016;10:325-6.

11. Huang J, Liu S, He R, Fang S, Lu W, Wu J, Liang H, Zhang Y. Factors associated with residents' contract behavior with family doctors in community health service centers: a longitudinal survey from China. PLoS One. 2018;13:e0208200.

12. Yao $\mathrm{D}$, Xie $\mathrm{Q}$, Song $\mathrm{W}$, Liu $\mathrm{D}$. The policy process research of family doctor system in China: from the perspective of the multiple-streams theory. Public Policy Adm Res. 2017:1:47-57.

13. Guidance on promoting the implementation of family physician contract service in Shaanxi Province. Health Commission of Shaanxi Province. 2016. http://sxwjw.shaanxi.gov.cn/ywgz/tzgg/gzdt_872/201611/t20161107_18035 71.html. Accessed 6 May 2020. (In Chinese).

14. Yin J, Wei X, Li H, Jiang Y, Mao C. Assessing the impact of general practitioner team service on perceived quality of care among patients with non-communicable diseases in China: a natural experimental study. Int J Qual Health Care. 2016;28:554-60.

15. Kuang L, Liang Y, Mei J, Zhao J, Wang Y, Liang H, Shi L. Family practice and the quality of primary care: a study of Chinese patients in Guangdong Province. Fam Pract. 2015:32:557-63.

16. Li L, Zhong C, Mei J, Liang Y, Li L, Kuang L. Effect of family practice contract services on the quality of primary care in Guangzhou, China: a crosssectional study using PCAT-AE. BMJ Open. 2018;8:e021317.

17. Huang J, Lu W, Wang L, Zhang T, Liu C, Liu S, Liang H, Zhang Y, Guo D. A preliminary effect analysis of family doctor and medical insurance payment coordination reform in Changning District of Shanghai, China. BMC Fam Pract. 2019;20:60.

18. Huang J, Zhang T, Wang L, Guo D, Liu S, Lu W, Liang H, Zhang Y, Liu C. The effect of family doctor-contracted services on noncommunicable disease self-management in Shanghai, China. Int J Health Plann Manag. 2019;34: 935-46.

19. Knight JC, Dowden JJ, Worrall GJ, Gadag VG, Murphy MM. Does higher continuity of family physician care reduce hospitalizations in elderly people with diabetes? Popul Health Manag. 2009;12:81-6.

20. Romskaug R, Skovlund E, Straand J, Molden E, Kersten H, Pitkala KH, Lundqvist C, Wyller TB. Effect of clinical geriatric assessments and collaborative medication reviews by geriatrician and family physician for improving health-related quality of life in home-dwelling older patients 
receiving Polypharmacy: a cluster randomized clinical trial. JAMA Intern Med. 2019;180:181-9.

21. Jabbari Beyrami H, Doshmangir L, Ahmadi A, Asghari Jafarabadi M, Khedmati Morasae E, Gordeev VS. Impact of rural family physician programme on maternal and child health indicators in Iran: an interrupted time series analysis. BMJ Open. 2019;9:e21761.

22. Chinhoyi RL, Zunza M, Von Pressentin KB. The impact of family physician supply on district health system performance, clinical processes and clinical outcomes in the Western Cape Province, South Africa (2011-2014). Afr J Prim Health Care Fam Med. 2018;10:e1-4.

23. Sun $X$, Song $X$, Kong D. Effect of family practice contract services on community hypertension management. Chronic Pathematology J. 2020;21: 1359-61 (in Chinese).

24. Shi L, Starfield B, Kennedy B, Kawachi I. Income inequality, primary care, and health indicators. J Fam Pract. 1999:48:275-84.

25. Ford-Gilboe M, Wathen CN, Varcoe C, Herbert C, Jackson BE, Lavoie JG, Pauly BB, Perrin NA, Smye V, Wallace B, et al. How equity-oriented health care affects health: key mechanisms and implications for primary health care practice and policy. Milbank Q. 2018;96:635-71.

26. Dover DC, Belon AP. The health equity measurement framework: a comprehensive model to measure social inequities in health. Int J Equity Health. 2019;18:36.

27. Wilson IB, Cleary PD. Linking clinical variables with health-related quality of life: a conceptual model of patient outcomes. JAMA. 1995;237:59-65.

28. Mujica-Mota RE, Roberts M, Abel G, Elliott M, Lyratzopoulos G, Roland M, Campbell J. Common patterns of morbidity and multi-morbidity and their impact on health-related quality of life: evidence from a national survey. Qual Life Res. 2015;24:909-18.

29. R B. EuroQol: the current state of play. Health Policy. 1996;37:53-72.

30. Wang HM, Patrick DL, Edwards TC, Skalicky AM, Zeng HY, Gu WW. Validation of the EQ-5D in a general population sample in urban China. Qual Life Res. 2012;21:155-60

31. Liu GG, Wu H, Li M, Gao C, Luo N. Chinese time trade-off values for EQ-5D health states. Value Health. 2014;17:597-604.

32. Su M, Zhou Z, Si Y, Wei X, Xu Y, Fan X, Chen G. Comparing the effects of China's three basic health insurance schemes on the equity of healthrelated quality of life: using the method of coarsened exact matching. Health Qual Life Outcomes. 2018;16:41.

33. Wang Y, Shi J, Du L, Huang H, Wang L, Zhu J, Li H, Bai Y, Liao X, Mao A, et al. Health-related quality of life in patients with esophageal cancer or precancerous lesions assessed by EQ-5D: a multicenter cross-sectional study. Thorac Cancer. 2020;11:1076-89.

34. lacus SM, King G, Porro G. Causal inference without balance checking: coarsened exact matching. Polit Anal. 2017;20:1-24.

35. M B, S I, G K. cem: Coarsened exact matching in Stata. Stata J. 2009;9:52446.

36. O'Donnell O, Van Doorslaer E, Wagstaff A, Lindelow M. Analyzing Health Equity Using Household Survey Data; 2007.

37. Van de Poel E, O'Donnell O, Van Doorslaer E. Are urban children really healthier? Evidence from 47 developing countries. Soc Sci Med. 2007;65: 1986-2003.

38. Sullivan PW, Ghushchyan V. Preference-based EQ-5D index scores for chronic conditions in the United States. Med Decis Mak. 2006;26:410-20.

39. Costa-Font J, Gil J. What lies behind socio-economic inequalities in obesity in Spain? A decomposition approach. Food Policy. 2008:33:61-73.

40. Aubin M, Vezina L, Verreault R, Fillion L, Hudon E, Lehmann F, Leduc $Y$, Bergeron R, Reinharz D, Morin D. Family physician involvement in cancer care and lung cancer patient emotional distress and quality of life. Support Care Cancer. 2011:19:1719-27.

41. Haas BK. A multidisciplinary concept analysis of quality of life. West J Nurs Res. 1999:21:728-42.

42. AlRuthia Y, Alwhaibi M, Almalag H, Almosabhi L, Almuhaya M, Sales I, Albassam AA, Alharbi FA, Mansy W, Bashatah AS, Asiri Y. The relationship between trust in primary healthcare providers among patients with diabetes and levels of depression and anxiety. PLoS One. 2020:15:e0239035.

43. Bayati M, Keshavarz K, Lotfi F, KebriaeeZadeh A, Barati O, Zareian S, Amiri A, Delavari S. Effect of two major health reforms on health care cost and utilization in Fars Province of Iran: family physician program and health transformation plan. BMC Health Serv Res. 2020;20:382.
44. Richard L, Furler J, Densley K, Haggerty J, Russell G, Levesque JF, Gunn J. Equity of access to primary healthcare for vulnerable populations: the IMPA CT international online survey of innovations. Int J Equity Health. 2016;15:64.

45. Zhao Y, Lin J, Qiu Y, Yang Q, Wang X, Shang X, Xu X. Demand and signing of general practitioner contract service among the urban elderly: a population-based analysis in Zhejiang Province, China. Int J Environ Res Public Health. 2017;14:356.

46. Wang H, Shi L, Han X, Zhang J, Ma Y, Yang X, Liu M, Fan L, Lou F. Factors associated with contracted services of Chinese family doctors from the perspective of medical staff and consumers: a cross-sectional study. BMC Health Serv Res. 2019;19:986

47. R J, H F. Advances in Supply-demand Study of Contracted Family Doctor Services in China. Chinese Gen Pract. 2020;23:3131-8 (in Chinese).

48. $X Y Z, X N Z, P Q F$. A Meta-analysis of the signing rates of family doctors in China. Chinese J Health Stat. 2019:36:255-7 260 (in Chinese).

49. Chen A, Feng S, Tang W, Zhang L. Satisfaction with service coverage and drug list may influence patients' acceptance of general practitioner contract service: a cross-sectional study in Guangdong, China. BMC Health Serv Res. 2019:19:251.

50. Liu S, Wang L, Zhang T, Liu C, Liang H, Zhang Y, Guo D. Factors affecting the work competency and stability of family doctors in Shanghai: a tracking study. BMC Fam Pract. 2019:20:95.

51. Zhuo L, Xu L, Ye J, Sun S, Zhang Y, Burstrom $K$, Chen J. Time trade-off value set for EQ-5D-3L based on a nationally representative Chinese population survey. Value Health. 2018;21:1330-7.

\section{Publisher's Note}

Springer Nature remains neutral with regard to jurisdictional claims in published maps and institutional affiliations.
Ready to submit your research? Choose BMC and benefit from:

- fast, convenient online submission

- thorough peer review by experienced researchers in your field

- rapid publication on acceptance

- support for research data, including large and complex data types

- gold Open Access which fosters wider collaboration and increased citations

- maximum visibility for your research: over $100 \mathrm{M}$ website views per year

At BMC, research is always in progress.

Learn more biomedcentral.com/submissions 